\title{
Effect of acute treatment with a water-alcohol extract of Erythrina mulungu on anxiety-related responses in rats
}

G.M. Onusic ${ }^{1}$, R.L. Nogueira2, A.M.S. Pereira ${ }^{3}$ and M.B. Viana ${ }^{1}$

\section{Correspondence}

M.B. Viana

Laboratório de Psicofarmacologia

FFCLRP, USP

Av. Bandeirantes, 3900

14040-901 Ribeirão Preto, SP

Brasil

Fax: + 55-16-633-5668

E-mail: milena@usp.br

Research supported by CNPq and FAPESP.

Received O ctober 30, 2001 Accepted February 19, 2002

\author{
1Laboratório de Psicofarmacologia, Faculdade de Filosofia, Ciências e Letras \\ de Ribeirão Preto, U niversidade de São Paulo, Ribeirão Preto, SP, Brasil \\ ${ }^{2}$ Laboratório de Psicologia Comparativa, U niversidade Estácio de Sá, \\ Rio de Janeiro and Faculdade de Psicologia, Universidade de Ribeirão Preto, \\ Ribeirão Preto, SP, Brasil \\ ${ }^{3}$ Departamento de Biotecnologia Vegetal, Universidade de Ribeirão Preto, \\ Ribeirão Preto, SP, Brasil
}

\section{Abstract}

We investigated the effect of acute oral treatment with a water-alcohol extract of the inflorescence of Erythrina mulungu (EM, LeguminosaePapilionaceae) $(100,200$ and $400 \mathrm{mg} / \mathrm{kg})$ on rats submitted to different anxiety models: the elevated T-maze (for inhibitory avoidance and escape measurements), the light/dark transition, and the cat odor test. These models were selected for their presumed capacity to demonstrate specific subtypes of anxiety disorders as recognized in clinical practice. Treatment with $200 \mathrm{mg} / \mathrm{kg}$ EM impaired avoidance latencies (avoidance $1-200 \mathrm{mg} / \mathrm{kg}$ EM: $18 \pm 7 \mathrm{~s}$, control group: $40 \pm 9 \mathrm{~s}$; avoidance 2 - $200 \mathrm{mg} / \mathrm{kg}$ EM: $15 \pm 4 \mathrm{~s}$, control group: $110.33 \pm 38 \mathrm{~s}$ ) in a way similar to the reference drug diazepam (avoidance 1: $3 \pm 0.79 \mathrm{~s}$; avoidance $2: 3 \pm 0.76 \mathrm{~s}$ ), without altering escape. Additionally, the same treatments increased the number of transitions $(200 \mathrm{mg} / \mathrm{kg}$ EM: $6.33 \pm 0.90$, diazepam: $10 \pm 1.54$, control group: $2.78 \pm 0.60$ ) between the two compartments and the time spent in the lighted compartment in the light/dark transition model $(200 \mathrm{mg} / \mathrm{kg}$ EM: $39 \pm 7 \mathrm{~s}$; diazepam: $61 \pm 9 \mathrm{~s}$; control group: $14 \pm 4 \mathrm{~s}$ ). The dose of $400 \mathrm{mg} / \mathrm{kg}$ EM also increased this last measurement $(38 \pm 8 \mathrm{~s})$. These results were not due to motor alterations since no significant effects were detected in the number of crossings or rearings in the arena. Furthermore, neither EM nor diazepam altered the behavioral responses of rats to a cloth impregnated with cat odor. These observations suggest that EM exerts anxiolytic-like effects on a specific subset of defensive behaviors, particularly those that have been shown to be sensitive to low doses of benzodiazepines.

\section{Key words}

- Erythrina mulungu

- Anxiety

- Animal models 
There are over 100 species of plants of the genus Erythrina in the tropics. Erythrina species are known to produce alkaloids, flavonoids and terpenes $(1,2)$. Pharmacological assays performed with the alkaloids of Erythrina americana have shown anticonvulsant, hypnotic and analgesic effects (3). The species Erythrina glauca and Erythrina lysistemon have been reported to possess antiviral and antibacterial activity $(1,4)$. Furthermore, analgesic and anti-inflammatory effects were observed for an aqueous extract of the stem bark of Erythrina senegalensis (5).

Erythrina mulungu (EM) (LeguminosaePapilionaceae), popularly known as mulungu, is a medium-sized branched tree native to Southern Brazil (6). The plant produces a reddish inflorescence at the end of its branches, the reason why it is sometimes called "flor de coral" (coral flower). In herbal medicine, a leaf or bark decoction or tincture from mulungu is considered to calm agitation and other disorders of the nervous system, including insomnia (7). There have also been some reports on the therapeutic use of the plant's inflorescence by herbal practitioners. Nevertheless, despite its wide popular utilization, the supposed therapeutic properties of EM only recently began to be evaluated in preclinical studies. Thus, evidence from a previous study (Viana GSB, personal communication) has shown that acute treatment with a stem bark water-alcohol extract of EM increases both the number of entries and the time spent by mice in the open arms of the elevated plus-maze model of anxiety (8).

Although it is one of the most widely used animal models of anxiety, the elevated plus-maze (8) has been said to be a "mixed" model, that is, one that does not allow the discrimination between different types of fear/anxiety (9). Since clinical anxiety comprises distinctive pathological conditions, such as generalized anxiety disorder (GAD), panic and phobias, which are unequally af- fected by pharmacological therapy (10), efforts have been made to validate experimental models specifically related to certain kinds of anxiety disorders (11-13). In this respect, pharmacological studies performed with the elevated T-maze (14), which is derived from the elevated plus-maze (8), are compatible with the view that the two tasks measured in the model, inhibitory avoidance and escape from the open arms, may be correlated with human GAD and panic, respectively $(14,15)$. Also, in a way similar to their therapeutic profile in GAD, benzodiazepine agonists seem to decrease anxiety responses measured in another animal model of anxiety, i.e., the light/dark transition model $(16,17)$. On the other hand, the behavioral responses observed in the cat odor test $(11,18,19)$ were shown to be resistant to different classes of anxiolytic drugs. This observation has led to the proposition of a relationship between the test and the symptomatic aspects of human phobias $(11,18,19)$.

Taking the above evidence into account, the purpose of the present study was to further investigate the acute anxiolytic potential of EM through the use of animal models specifically correlated with certain kinds of anxiety disorders: the elevated T-maze, the light/dark transition model and the cat odor test (see apparatus description in 15,17,18). In order to avoid confusing results due to treatment effects on locomotor activity, animals were also tested in an arena (see Ref. 15 for apparatus specification). In all cases, diazepam (DZP) was used as the reference drug.

An inflorescence water-alcohol extract was used since the procedure of scraping the bark out of the tree often damages the plant. Inflorescences were collected at Rifaina, São Paulo, and the exsiccatae deposited at the Department of Vegetal Biotechnology of the University of Ribeirão Preto under the code HPM-0032. Fresh inflorescences of EM(200 g) were extracted with $30 \%$ water and $70 \%$ ethanol. The plant extract was macerated 
over a period of 10 days. The crude extract was then filtered and heated $\left(50^{\circ} \mathrm{C}\right)$ until it was reduced to $50 \%$ of its original volume for alcohol evaporation. The liquid obtained was frozen and subsequently lyophilized to give a dry residue $(5 \mathrm{~g})$. For administration, EM and DZP (Sigma, St. Louis, MO, USA) were suspended in saline with $2 \%$ Tween 80 . Control animals were injected with a solution of saline-2\% Tween 80 . All compounds were prepared on the day of the experimental sessions.

For the experiments with the elevated T-maze, male Wistar rats (250-300 g) were housed 5-6 per cage for 5 days. On the fourth day, animals were submitted to a 30-min prior forced exposure to one of the open arms of the maze. It has been proposed that pre-exposure decreases the latency to leave this arm in a later trial, assuring that during measurements of escape animals are really escaping from aversion and not simply ambling (15). On the fifth day, rats were randomly allocated to different treatment groups, receiving by gavage one of the doses of the water-alcohol extract of the EM inflorescence $(100,200$ or $400 \mathrm{mg} / \mathrm{kg})$, DZP (4 mg/ $\mathrm{kg}$ ) or vehicle in a volume of $10 \mathrm{ml} / \mathrm{kg}$. Thirty minutes later, each animal was placed at the distal end of the enclosed arm of the maze and the time taken by the rat to leave this arm with the four paws was recorded in three consecutive trials (baseline latency, avoidance 1 and 2), at 30-s intertrial intervals. Following avoidance training (30 s), rats were placed at the end of the right open arm of the maze and the latency to leave this arm with the four paws was recorded for three consecutive times (escape 1,2 and 3), again with 30 -s intertrial intervals. Immediately after being tested in the elevated $\mathrm{T}$ maze, each animal was placed for $5 \mathrm{~min}$ in an arena with the floor divided into nine equal squares for the evaluation of the total number of lines crossed and frequency of rearings.

After the experiments with the arena, each animal was individually housed for 5 additional days. On the fifth day, rats again received by gavage the same doses of EM, DZP or vehicle and 30 min later were submitted to the light/dark transition model. For this test, each rat was placed in the middle of the lighted compartment facing the doorway separating the two compartments. The behavior of the animals was analyzed over a 5min period for the measurement of total number of transitions between the two compartments and time spent in the lighted compartment. After tests with the light/dark transition model, animals were submitted to the cat odor test. Two rats at a time were taken to

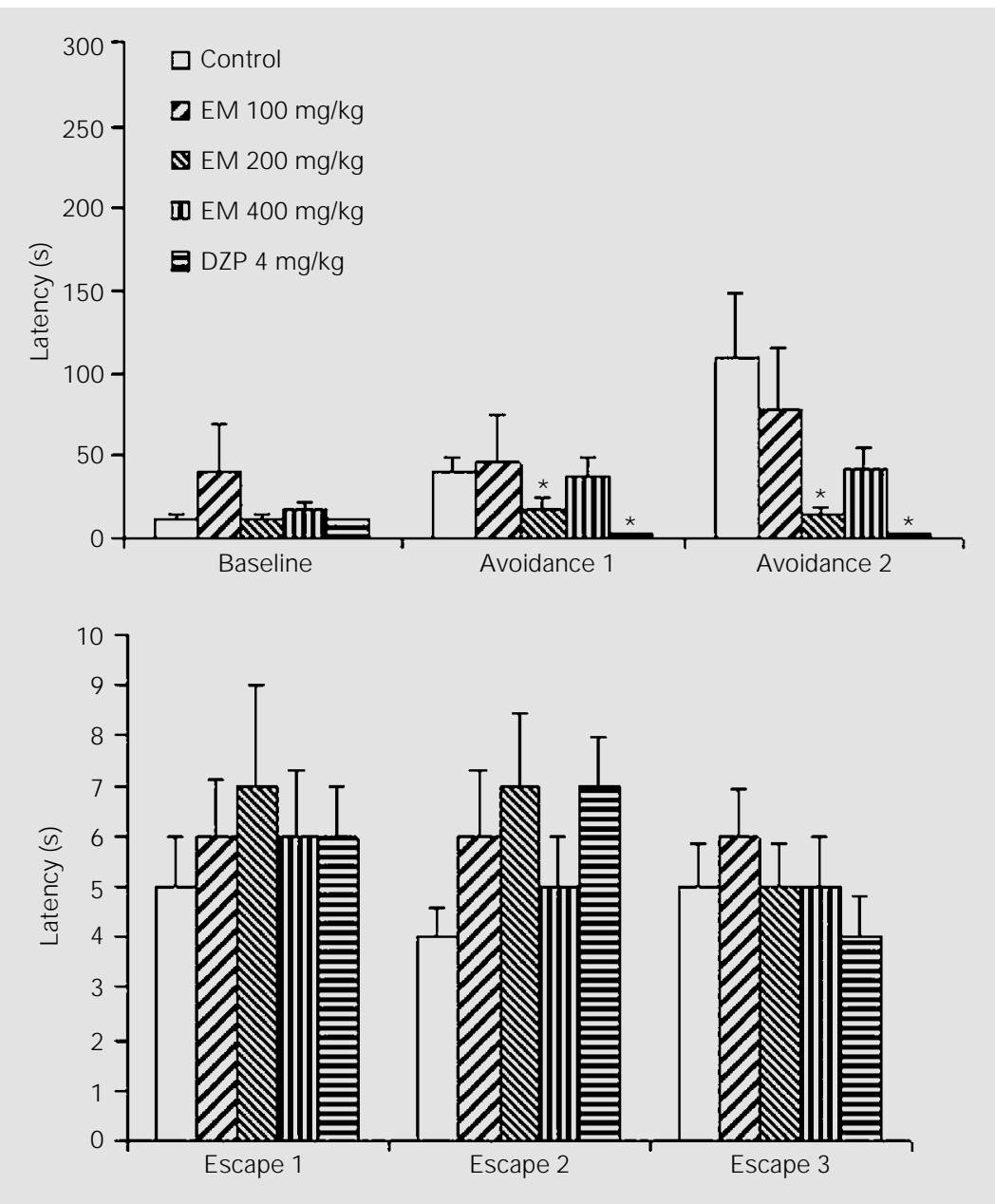

Figure 1. Effects of acute po administration of a water-alcohol extract of Erythrina mulungu (EM) and of diazepam (DZP) on the behavior of rats submitted to the avoidance (upper panel) and escape (lower panel) tasks of the elevated T-maze. Data are reported as means \pm SEM. $\mathrm{N}=9$ (control), $\mathrm{N}=10$ (EM $100 \mathrm{mg} / \mathrm{kg}), \mathrm{N}=9$ (EM $200 \mathrm{mg} / \mathrm{kg}), \mathrm{N}=9$ (EM $400 \mathrm{mg} / \mathrm{kg}$ ) and $\mathrm{N}=9$ (DZP $4 \mathrm{mg} / \mathrm{kg}$ ). ${ }^{*} \mathrm{P}<0.05$ compared to control (Duncan test). 
the experimental room in their individual home cages. The two home cages were then placed side by side and one odor cloth was placed on the top of each cage, at the end opposite to the food and water compartments. The cat odor was obtained by rubbing a damp cloth against the fur of male laboratory-housed domestic cats for $5 \mathrm{~min}$. For each rat, the number of contacts with the cloth (a distance of $5 \mathrm{~cm}$ or less from the cloth), as well as the time spent sheltering under the food and water compartment were quantified over a period of $5 \mathrm{~min}$.

Treatment with the dose of $200 \mathrm{mg} / \mathrm{kg}$ of the water-alcohol extract of the EM inflorescence impaired avoidance latencies in a way similar to DZP (Figure 1). Split-plot ANOVA showed a significant effect of treatment $[\mathrm{F}(4,41)=7.79, \mathrm{P}<0.001]$, trials $[\mathrm{F}(2,82)=$ 4.79, $\mathrm{P}<0.05]$ and of treatment versus trial interaction $[\mathrm{F}(8,82)=7.71, \mathrm{P}<0.001]$. Post hoc comparisons showed that both the group treated with $200 \mathrm{mg} / \mathrm{kg}$ EM and the group

Figure 2. Effects of acute po administration of a water-alcohol extract of Erythrina mulungu (EM) and of diazepam (DZP) on the behavior of rats submitted to the light/dark transition model. The upper panel shows the number of transitions between the two compartments and the lower panel shows the time spent by the animals in the lighted compartment. Data are reported as means \pm SEM. $\mathrm{N}=9$ (control), $\mathrm{N}=10$ (EM $100 \mathrm{mg} /$ $\mathrm{kg}), \mathrm{N}=9$ (EM $200 \mathrm{mg} / \mathrm{kg}), \mathrm{N}=9$ (EM $400 \mathrm{mg} / \mathrm{kg}$ ) and $\mathrm{N}=9$ (DZP $4 \mathrm{mg} / \mathrm{kg}) . * \mathrm{P}<0.05$ compared to control (Duncan test).
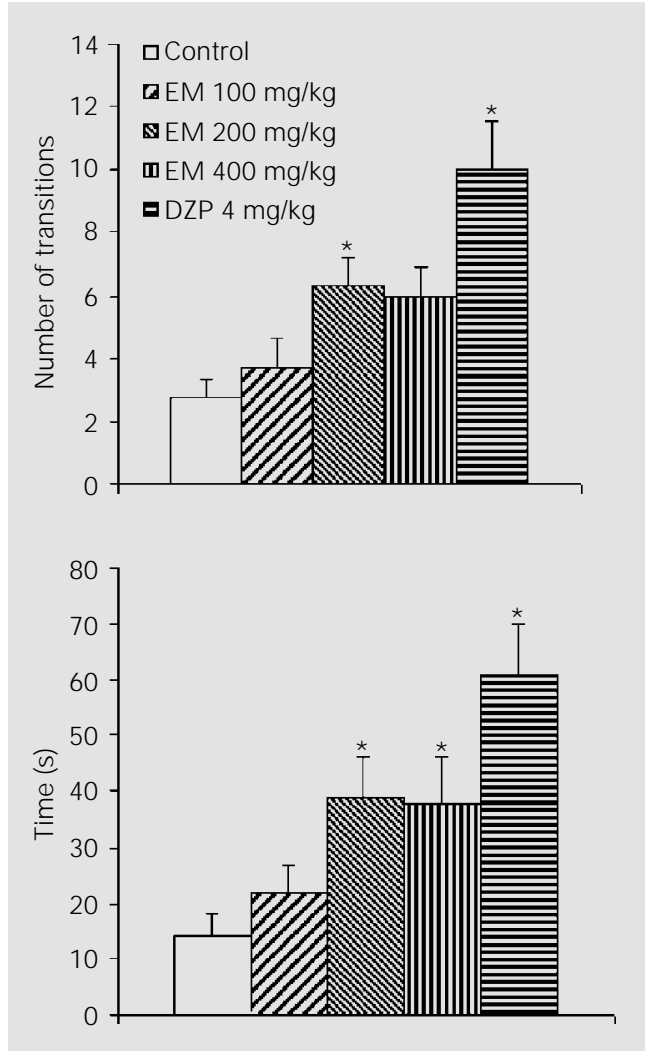

treated with DZP were significantly different from the control group in avoidance 1 and $2(\mathrm{P}<0.05$, Duncan post hoc test). Additionally, both measurements performed in the light/dark transition model were increased by the same treatments (Figure 2), i.e., the number of transitions between the two compartments and the time spent in the lighted compartment $(\mathrm{P}<0.05$, one-way ANOVA followed by the Duncan post hoc test). The dose of $400 \mathrm{mg} / \mathrm{kg}$ EM also significantly altered this last measurement $(\mathrm{P}<0.05$, Duncan post hoc test). On the other hand, escape latencies, locomotor activity (data not shown) and behavioral measurements in response to cat odor exposure (data not shown) were not altered by the treatments.

Since immediately after the experiments with the light/dark transition model the animals were submitted to the cat odor test, one may argue that the negative results obtained in the latter may be an effect of sequential testing. Nevertheless, a previous study performed in our laboratory (Andrade CLV and Zangrossi Jr $\mathrm{H}$, unpublished data) has shown that behavioral responses performed by rats during exposure to a cat odor are not affected by pre-exposure to other anxiety models, such as, for instance, the light/dark transition. Therefore, the absence of anxiolytic effects obtained with EM in the cat odor test supports previous studies $(11,18,19)$ showing that this condition is resistant to different pharmacological treatments.

Taken together, the present results indicate that acute po treatment with a wateralcohol extract of EM inflorescences altered anxiety-related responses that have been shown to be sensitive to low doses of benzodiazepines (14-17). This selective effect of EM may be related to the mechanism of action of some of its constituents. Alkaloids, for instance, seem to be ubiquitous in Erythrina plants and have been isolated from seeds, leaves, stalks, stems, barks, roots, pods and flowers (2). Moreover, it has been suggested that, on the basis of their pharmacolo- 
gical profile, the alkaloids present in some species of Erythrina may alter GABAergic neurotransmission (3). Nevertheless, additional studies are necessary to confirm this assumption.

A feasible explanation for the lack of a dose-response curve for the EM extract might be related to pharmacodynamics. It is possible, for instance, that increasing the extract doses causes a shift to a different primary mechanism of action. This hypothesis has been proved true for some anxiolytic compounds, i.e., the serotonergic drug buspirone. When tested in animal models of anxiety, buspirone produces an inverted U-shaped curve, which has been related to the release of corticosterone at doses close to the optimum dose for the anxiolytic effects of the drug (20).

Finally, it should be emphasized that since some pharmacological agents have been shown to ameliorate specific subtypes of anxiety disorders only after chronic treatment (10), further experiments with EM under this regimen of administration are warranted.

\section{Acknowledgments}

We are grateful to Afonso Paulo Padovan for technical assistance.

\section{References}

1. McKee TC, Bokesch HR, McCormick J L, Rashid MA, Spielvogel D, Gustafson KR, Alavanja MM, Cardellina J H \& Boyd MR (1997). Isolation and characterization of new anti-HIV and cytotoxic leads from plants, marine, and microbial organisms. J ournal of Natural Products, 60: 431-438.

2. Garcia-Mateos R, Soto-Hernández $M$ \& Kelly D (1998). Alkaloids form six Erythrina species endemic to Mexico. Biochemical Systematics and Ecology, 26: 545-551.

3. Garín-Aguilar MA, Luna JER, SotoHernández $M$, Valencia del Toro $G \&$ Vásquez MM (2000). Effect of crude extracts of Erythrina americana Mill. on aggressive behavior in rats. J ournal of Ethnopharmacology, 69: 189-196.

4. Rabe T \& van Staden J (1997). Antibacterial activity of South African plants used for medicinal purposes. J ournal of Ethnopharmacology, 56: 81-87.

5. Saidu K, Onah J, Orisadipe A, Olusola A, Wambebe C \& Gamaniel K (2000). Antiplasmodial, analgesic and anti-inflammatory activities of the aqueous extract of the stem bark of Erythrina senegalensis. J ournal of Ethnopharmacology, 71: 275280.

6. Lourenzi H (1992). Árvores Brasileiras: Manual de Identificação e Cultivo de Plantas. Plantarum Ltda., São Paulo, SP, Brazil.

7. Rodrigues VEG \& Carvalho DA (2001). Indicação, parte e preparo de plantas medicinais. In: Rodrigues VEG \& Carvalho DA (Editors), Plantas Medicinais do Cerrado. UFLA, Lavras, MG, Brazil.

8. Pellow S, Chopin P, File SE \& Briley M (1985). Validation of open:closed arm entries in the elevated plus-maze as a measure of anxiety in the rat. J ournal of Neuroscience Methods, 14: 149-167.

9. Handley SL \& MCBlane J W (1993). 5-HT drugs in animal models of anxiety. Psychopharmacology, 112: 13-20.

10. Nutt D (1991). Anxiety and its therapy: Today and tomorrow. In: Briley M \& File S (Editors), New Concepts in Anxiety. MacMillan Press, London, UK, 1-12.

11. J ohnston AL \& File SE (1988). Can animal tests of anxiety detect panic-promoting agents? Human Psychopharmacology, 3: 149-152.

12. Hendrie CA \& Weiss SM (1994). The development of an animal model of panic with predictive and face validity. In: Cooper SL \& Hendrie CA (Editors), Ethology and Pharmacology. J ohn Wiley \& Sons, Chichester, England, 111-132.

13. Griebel G, Blanchard DC, J ung A, Lee J C, Masuda CK \& Blanchard RJ (1995). Further evidence that the mouse defense test battery is useful for screening anxioIytic and panicolytic drugs: Effects of acute and chronic treatment with alprazolam. Neuropharmacology, 34: 1625-1633.

14. Graeff FG, Ferreira Neto $C \&$ Zangrossi J r $H$ (1998). The elevated T-maze as an ex- perimental model of anxiety. Neuroscience and Biobehavioral Reviews, 23: 237 246.

15. Custódio Teixeira R, Zangrossi J r H \& Graeff FG (2000). Behavioral effects of acute and chronic imipramine in the elevated T-maze model of anxiety. Pharmacology, Biochemistry and Behavior, 65: 571-576.

16. Crawley J N (1981). Neuropharmacologic specificity of a simple model for the behavioral actions of benzodiazepines. Pharmacology, Biochemistry and Behavior, 15: 695-699.

17. Sanchez C (1996). 5-HT1A receptors play an important role in the modulation of behavior of rats in a two-compartment black and white box. Behavioural Pharmacology, 129: 197-205.

18. Zangrossi J r H \& File SE (1992). Behavioral consequences in animal tests of anxiety and exploration of exposure to cat odor. Brain Research Bulletin, 29: 381388.

19. Zangrossi J r H \& File SE (1992). Chlordiazepoxide reduces the generalised anxiety, but not the direct responses, of rats exposed to cat odor. Pharmacology, Biochemistry and Behavior, 43: 1195-1200.

20. McNaughton N (1993). Stress and behavioral inhibition. In: Clare Stanford S, Salmon P \& GrayJ (Editors), Stress: From Synapse to Syndrome. Academic Press, San Diego, CA, USA. 